\title{
ARGVMENTVM VOLVMINIS PRIMI
}

\section{PRAEFATIO}

A. De classibus, in quas scholia ad Homeri Iliadem distribuuntur . . . . . . . . . . . . . . XI

B. De libris manuscriptis, quibus Scholia maiora servata sunt

I. De codicibus . . . . . . . . . . . . . XIII II. De papyris . . . . . . . . . . . . . XXXIV

C. De ratione, quae inter codices intercedit (vide stemma p. LVIII delineatum)

I. De codice Veneto A eiusque propinquis . . . . . XLV

II. De scholiis exegeticis . . . . . . . . . . . . . XLVIII

III. De fragmentis commentarii quattuorvirorum, quae in scholiis exegeticis exstant . . . . . . . . . LII IV. De scholiis classis $h$. . . . . . . . . . . . LVI

D. De testimoniis, h. e. de scholiis extra libros Homericos traditis . . . . . . . . . . . . . LX

E. De editionibus . . . . . . . . . . . . LXVII

F. De huius editionis ratione. . . . . . . . LXXIII

COMPENDIA

1. Auctores . . . . . . . . . . . . LXXXX

2. Tituli librorum ... . . . . . . . . LXXXIX

3. Abbreviationes ceterae minus usitatae . . . . . . . XCIX

4. Sigla librorum manuscriptorum . . . . . . . . . . . C

5. Nomina virorum doctorum selecta . . . . . . . . . . CII

SCHOLIA GRAECA

ad Iliadis librum A . . . . . . . . . . . . . . . . . . 3

ad Iliadis librum B . . . . . . . . . . . . . . . . . 163

ad Iliadis librum $\Gamma$. . . . . . . . . . . . . 353

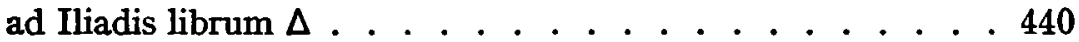

Addenda et Corrigenda (vide etiam p. CIII) . . . . . . 539 
